$11-15-2011$

\title{
Field-Effect Amperometric Immuno-Detection of Protein Biomarker
}

Jlapeng Wang

Cleveland State University

Siu-Tung Yau

Cleveland State University, s.yau@csuohio.edu

Follow this and additional works at: https://engagedscholarship.csuohio.edu/enece_facpub

Part of the Biomedical Commons

How does access to this work benefit you? Let us know!

Publisher's Statement

NOTICE: this is the author's version of a work that was accepted for publication in Biosensors \& Bioelectronics. Changes resulting from the publishing process, such as peer review, editing, corrections, structural formatting, and other quality control mechanisms may not be reflected in this document. Changes may have been made to this work since it was submitted for publication. A definitive version was subsequently published in Biosensors \& Bioelectronics, 29, 1, (11-15-2011); 10.1016/j.bios.2011.07.072

\section{Original Citation}

Wang, J., , \& Yau, S. (2011). Field-effect amperometric immuno-detection of protein biomarker. Biosensors and Bioelectronics, 29(1), 210-214. doi:10.1016/j.bios.2011.07.072

\section{Repository Citation}

Wang, Jlapeng and Yau, Siu-Tung, "Field-Effect Amperometric Immuno-Detection of Protein Biomarker" (2011).

Electrical Engineering \& Computer Science Faculty Publications. 63.

https://engagedscholarship.csuohio.edu/enece_facpub/63

This Article is brought to you for free and open access by the Electrical Engineering \& Computer Science Department at EngagedScholarship@CSU. It has been accepted for inclusion in Electrical Engineering \& Computer Science Faculty Publications by an authorized administrator of EngagedScholarship@CSU. For more information, please contact library.es@csuohio.edu. 


\title{
Field-effect amperometric immuno-detection of protein biomarker
}

\author{
Jiapeng Wang ${ }^{a}$, Siu-Tung Yau ${ }^{\mathrm{a}, \mathrm{b}, *}$ \\ ${ }^{a}$ Department of Electrical and Computer Engineering, Cleveland State University, Cleveland, OH 44115, USA \\ b The Applied Bioengineering Program, Cleveland State University, Cleveland, $\mathrm{OH} 44115, \mathrm{USA}$
}

\section{Introduction}

Biomarkers used for clinical testing of certain types of cancer are specific proteins such as prostate-specific antigen (PSA) (for prostate cancer), carcinoma antigen 125 (CA 125) (for ovarian cancer), cancer antigen 15-3 (CA 15-3) (for breast cancer), and carcinoembryonic antigen (CEA) (for colon cancer). Development of sensitive detection techniques for the detection of low-concentration cancer biomarkers present in the early stage of the disease is crucial for the outcome of the treatment of the disease (Rasooly and Jacobson, 2006; Warsinke, 2009). Electrochemical immunosensors appear to be a suitable platform for establishing biomarker detection techniques (Wang, 2006). In particular, since they allow fast real-time measurements and device miniaturization, electrochemical immunosensors are potentially suitable for the point-of-care approach to biomarker assay (Warsinke, 2009).

Recent development in the detection of biomarkers includes several noted works. In a bio-barcode assay for PSA (Thaxton et al., 2009), gold nanoparticles, functionalized with DNA and PSAspecific antibodies, were used to interact through immuno-reaction with magnetic microparticles that had been first functionalized with PSA-specific antibodies and subsequently mixed with the serum sample containing the PSA target. After magnetic separation, the PSA-specific DNA barcodes were released into a solution and detected using scanometric assay. The detection limit of this bio-barcode PSA assay was $330 \mathrm{fg} / \mathrm{mL}$ serum. An amperometric immunosensor for the simultaneous detection of two cancer biomarkers has been constructed on two iridium oxide electrodes (1-mm diameter) patterned on a glass substrate (Wilson, 2005). Capture antibodies were immobilized on the porous iridium oxide electrodes by covalent attachment using (3-aminopropyl) triethoxysilane and glutaraldehyde. The spatial separation of the electrodes $(2.5 \mathrm{~mm})$ enabled simultaneous electrochemical immunoassays of CEA and $\alpha$-fetoprotein to be conducted without cross-talk between the electrodes. The biomarkers were measured using electrochemical ELISA, and detection was achieved by electrochemically oxidizing alkaline phosphatasegenerated hydroquinone. The sensor had detection limits of 1.2, and $1 \mathrm{ng} / \mathrm{mL}$ for CEA and $\alpha$-fetoprotein, respectively. A novel CA 125 immunosensor was prepared by co-immobilization of CA 125 and thionine, which was used as an electron transfer mediator, on a modified carbon electrode (Wu et al., 2007). Antibodies labeled with horseradish peroxidase (HRP) were used to bind CA 125 via immuno-conjugation. Hydrogen peroxide $\left(\mathrm{H}_{2} \mathrm{O}_{2}\right)$, the substrate of HRP, was released to the sensor, and CA 125 was detected by measuring the electrode current produced due to the HRP-catalyzed reduction of $\mathrm{H}_{2} \mathrm{O}_{2}$. The sensor showed a linear range of $2-75 \mathrm{U} / \mathrm{ml}$ and a detection limit of $1.8 \mathrm{U} / \mathrm{ml}$.

Recently, a novel field-effect enzymatic detection (FEED) technique, in which an external gating voltage was used to induce an electric field at the enzyme-electrode interface to amplify the signal current of an enzyme-based biosensor, has been developed (Choi and Yau, 2009). This technique was used to lower the detection limit of molecular analytes from the milli-molar $\left(10^{-3} \mathrm{M}\right)$ level obtained in the absence of the gating voltage down to the pico-molar $\left(10^{-12} \mathrm{M}\right)$ level achieved when the gating voltage was 


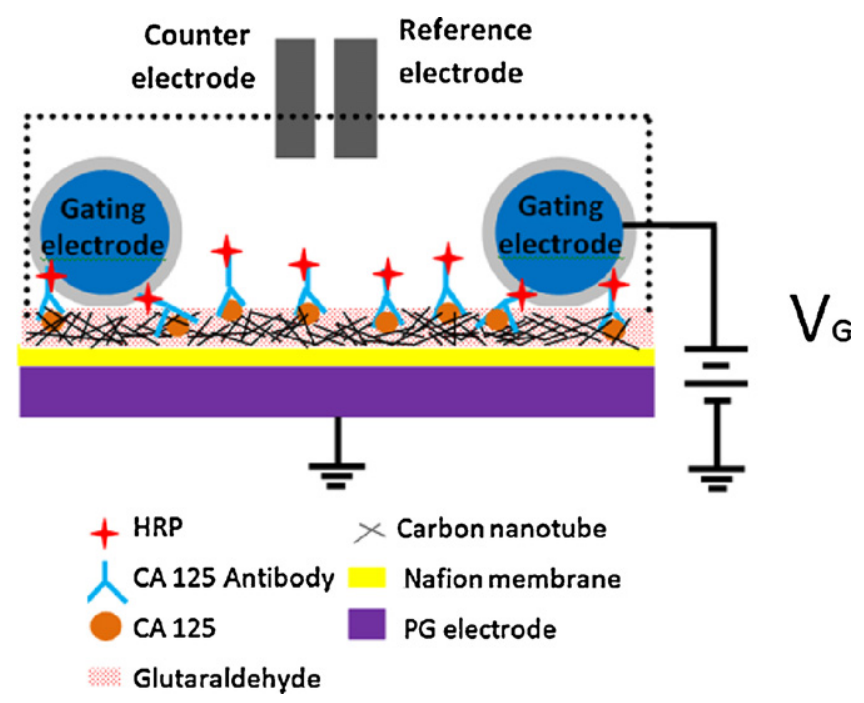

Fig. 1. A cross-sectional view of the detection system. The PG electrode with the multilayers of materials deposited on it depicts the structure of the detecting electrode. The gating electrodes are represented by the circular structures, which consist of a copper wire (the blue circles) and a thin layer of insulator (the shaded shells made of enamel). The gating voltage $V_{G}$ is used to induce an electric field at the interface between the sample solution and the detecting electrode. (For interpretation of the references to color in this figure legend, the reader is referred to the web version of the article.)

applied. Compared to the conventional field-effect-transistor (FET) biosensor, which employs the FET to provide a reference current, the FEED technique features a voltage-controlled amplification of the signal current. The signal current is produced by quantum tunneling of electrons, which depends critically on the distance electrons travel by means of tunneling and the potential energy profile of the tunnel structure. The FEED technique allows the energy profile of the tunnel structure to be changed using the gating voltage to increase the electron transfer rate. Therefore, the main advantage of the new technique is the voltage-controlled amplification of the signal current. In the work reported here, the FEED technique was applied to the enzyme-linked amperometric immuno-sensing scheme and the feasibility of using this new detection approach as a biomarker detection technique was demonstrated by the detection of the biomarker CA 125 , using electrodes modified with carbon nanotube. The incorporation of the two detection methods has resulted in a reagentless assay approach (Wang, 2005; Weiss et al., 2007), another advantage of the reported technique, which does not use electron transfer mediators and the substrate of the enzyme used to label the secondary antibody. As the result of the signal amplification, the detection limit of the detection system was lowered from $4.9 \mathrm{U} / \mathrm{ml}$ to $0.9 \mathrm{U} / \mathrm{ml}$.

\section{Materials and methods}

Fig. 1 shows a cross-sectional view of the detection system used in the experiment. The detection system consists of a conventional three-electrode (counter electrode, reference electrode and working/detecting electrode) electrochemical cell modified with additional gating electrodes for applying a gating voltage $V_{G}$ to the detecting (working) electrode. A piece of $0.5 \mathrm{~mm}$-diameter copper wire coated with a thin layer of insulator (enamel) was bent to form a U-shaped structure and was attached on the detecting electrode close to the exposed area using nonconductive epoxy as the gating electrode. A variable dc power supply was connected between the gating electrode and the detecting electrode to provide the gating voltage $V_{G}$. The principle of the field-effect enzymatic detector is described previously (Choi and Yau, 2009). Disks of pyrolytic graphite $(\mathrm{PG})(1 \mathrm{~cm} \times 1 \mathrm{~cm})$ were used as the basic electrode. The PG electrode was modified first with a thin layer of Nafion (Nafion 117, Fluka). The Nafion membrane was used to enhance the binding of the nanotube layer to the PG electrode. Single-walled carbon nanotubes (Carbon Solutions) were dissolved in dimethylformamide. The nanotube solution was then mixed with $1 \%$ glutaraldehyde solution (Sigma-Aldrich) and a drop of the mixture was placed on the Nafion layer to host the biomarker. The preparation of nanotube solution and its handling were carried out in a chemical hood in order to eliminate exposure to aerosol release. A mask was used to expose a $0.5 \mathrm{~mm} \times 0.5 \mathrm{~mm}$ area of the modified PG electrode. An $8 \mu$ l drop of a solution containing CA-125 (CA-125 ELISA, Signosis), the analyte, was deposited on the exposed area and the electrode was incubated for $22 \mathrm{~h}$, after which the electrode was rinsed with de-ionized water. The detecting electrode was formed by placing a $25 \mu \mathrm{l}$ drop of solution containing $1 \mathrm{ng} / \mathrm{ml}$ of antibody labeled with HRP (CA-125 ELISA, Signosis) on the exposed area and incubating the electrode for $45 \mathrm{~min}$. The same antibody concentration $(1 \mathrm{ng} / \mathrm{ml})$ was used for the incubation of all electrodes. The CA 125 antibody was monoclonal and has an affinity constant of $1.0 \times 10^{9} \mathrm{M}^{-1}$ (Boerman et al., 1990). This protein immobilization method has been used to immobilized other biomarkers (Bollo et al., 2007; Yu et al., 2005). The antibody was bound to CA-125 due to immuno-reaction. In Fig. 1, the PG electrode with the multilayers of materials deposited on it depicts the structure of the detecting electrode. The advantage of immobilizing the antigen on the electrode without using the primary antibody is that the passage for electron transfer from the enzyme used to label the secondary antibody to the electrode is shortened and therefore signal current is increased. Note that without nanotubes the signal would become weak. This is likely to be due to the better electrical conductivity provided by the nanotubes and the fact that CA 125 was immobilized on the electrode by being entrapped in the nanotubes.

Voltammetric (cyclic and linear) measurements were made to obtain the detection signal. A commercial $\mathrm{Ag} / \mathrm{AgCl}(3 \mathrm{M} \mathrm{KCl})$ electrode was used as the reference electrode, and a platinum wire was used as the counter electrode. The volume of the electrochemical cell was $1 \mathrm{ml}$. The cell was driven by a commercial electrochemical controller (CHI 660C Work Station). A potential scan rate of $50 \mathrm{mV} / \mathrm{s}$ was used in recording voltammograms. Phosphate buffer solution (PBS, 0.1 M at pH 7) was prepared using de-ionized water (18.2 M $\Omega$ $\mathrm{cm}$ ). Commercially available hydrogen peroxide (Fisher scientific, $30 \%$ concentration) was diluted to the concentrations used in the experiment and was stored in plastic containers. All measurements were made with deaerated PBS at room temperature. Reproducible results were obtained by repeating each measurement multiple times.

\section{Results and discussion}

In carrying out the detection, control experiments have been performed repeatedly using different types of electrode in order to avoid possible misinterpretation of the measurement results. Fig. S1(a) shows several cyclic voltammograms (CVs), which are used to validate the detection signal of CA-125. The CVs were obtained in PBS under different electrode conditions. CV1 was obtained with a modified PG electrode, upon which CA-125 $(200 \mathrm{U} / \mathrm{ml})$ was immobilized. The CA-125-immobilized electrode was then incubated with the HRP-labeled antibody and then rinsed with de-ionized water. The electrode now contained the antigen-antibody immuno-structure on its surface and it is referred to as the detecting electrode. CV2 was obtained with the detecting electrode. CV1 is featureless while CV2 shows an increased charging current and a pair of redox peaks with a formal potential of $-0.42 \mathrm{~V}$ and a peak-to-peak separation of $20 \mathrm{mV}$. Previous works on the 
direct electron transfer associated with immobilized HRP show that the formal potential of this redox process is between $-0.5 \mathrm{~V}$ and $-0.35 \mathrm{~V}$ vs. $\mathrm{Ag} / \mathrm{AgCl}$ (Ferri et al., 1998; Zhang et al., 2004). Thus, the redox peaks in CV2 indicate the occurrence of the immunological binding between CA-125 and its antibody and, therefore, the presence of the antigen-antibody immuno-structure on the electrode. The small peak-to-peak separation of $20 \mathrm{mV}$ indicates reversible interfacial electron transfer. The increased charging current is also consistent with the presence of the antibody on the electrode since the antibody has increased the effective area of the electrode surface exposed to the solution as shown in Fig. 1. To eliminate the possibility that residual unbound antibody on the electrode may generate signal, HRP-labeled antibody $(1 \mathrm{ng} / \mathrm{ml})$ was immobilized on the modified electrode, the electrode without the presence of CA-125, and CVs were obtained. CV3, which was obtained with such electrode, is featureless without the presence of the redox peaks. The reduced charging current compared to CV2 is consistent with the absence of CA-125 on the electrode. CV4 shows that the redox signal becomes weak if carbon nanotubes are not used. Note that carbon nanotubes rather than carbon powder was used due to the significantly smaller electrical resistivity (Chiodarelli et al., 2011; Nakazawaa et al., 2004).

Alternatively, the immunological binding was confirmed by testing the enzymatic activity of HRP. Fig. S1(b) shows four CVs obtained using a detecting electrode $(200 \mathrm{U} / \mathrm{ml}$ of CA-125), an electrode containing the antigen-antibody immuno-structure, in different concentrations of $\mathrm{H}_{2} \mathrm{O}_{2}$. The electrode responds to $\mathrm{H}_{2} \mathrm{O}_{2}$ by progressively increasing the cathodic current due to the reduction of $\mathrm{H}_{2} \mathrm{O}_{2}$ catalyzed by HRP. On the contrary, such response to $\mathrm{H}_{2} \mathrm{O}_{2}$ was not observed using a CA-125-immobilized electrode. Note that although the CVs show very weak and broadened redox peaks as indicated by the arrows or no peaks at all, the fact that the electrode's cathodic current responds to $\mathrm{H}_{2} \mathrm{O}_{2}$ indicates the enzymatic activity of HRP as previously observed (Andreu et al., 2007).

For the detection of CA-125, modified electrodes that have been incubated with solutions containing different CA-125 concentrations and subsequently incubated with the same amount of HRP-labeled antibody ( $1 \mathrm{ng} / \mathrm{ml}$ ) were used as detecting electrodes. The detection signal was obtained by measuring the peak current of the reduction peak of HRP in the linear voltammograms (LVs) of different detecting electrodes. Fig. 2(a) shows the LVs of 3 detecting electrodes, which were incubated with different CA- 125 concentrations, obtained in the absence of the gating voltage. The reduction peak currents were determined using the baseline displayed in the figure. The LVs show that as the CA-125 concentration is increased, the reduction peak current increases. The inset in Fig. 2(a) shows the CA-125 calibration curve of the detection system obtained with different detecting electrodes, i.e. $3,7,15,50,100,200 \mathrm{U} / \mathrm{ml}$, in the absence of the gating voltage. The detection limit was estimated to be $4.9 \mathrm{U} / \mathrm{ml}$, using the signal $/$ noise $=3$ method. The curve shows that the 3 and $7 \mathrm{U} / \mathrm{ml}$ data points almost coincide with each other.

The effect of applying $V_{G}$ on the detection signal was studied and it was found that the reduction-peak current increased as $V_{G}$ was increased. Fig. 2(b) shows four LVs obtained with a detecting electrode, which has been incubated with $200 \mathrm{U} / \mathrm{ml} \mathrm{CA}-125$. The four CVs were obtained with $V_{G}=0,0.1,0.2,0.3 \mathrm{~V}$, respectively, and the corresponding peak currents of the reduction peaks are $0.04,0.3,0.4$, and $0.58 \mu \mathrm{A}$ as measured using the baseline. Previously, the increase in the signal current of the bio-detector, which is used in this work, caused by applying $V_{G}$ in the positive polarity was attributed to the reduction of the height of the tunnel barrier between the active site of the enzyme and the electrode. $V_{G}$ induces an electric field at the enzyme-electrode interface, and the field reduces the effective height of the tunnel barrier, resulting in an increase in the tunnel rate of electrons (Choi and Yau,
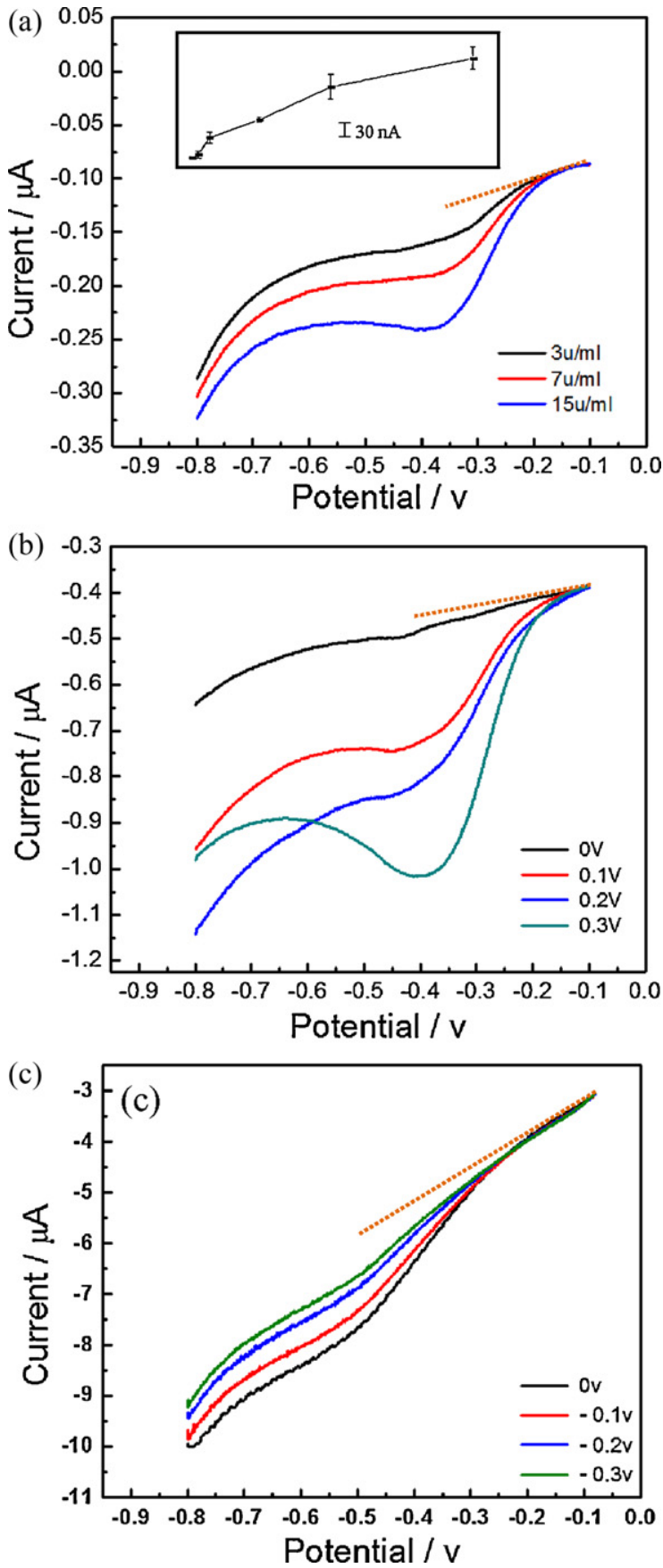

Fig. 2. (a) LVs of 3 detecting electrodes, which were immobilized with different CA 125 concentrations. The reduction peak currents are indicated using the baseline. Inset: the calibration curve of detection of CA-125 obtained with different detecting electrodes. (b) Four LVs obtained with a detecting electrode, which has been incubated with $200 \mathrm{U} / \mathrm{mlCA}-125$. The LVs were obtained with $V_{G}=0,0.1,0.2,0.3 \mathrm{~V}$. (c) The effect of increasing $V_{G}$ in the negative polarity on the signal current is demonstrated with a larger $200 \mathrm{U} / \mathrm{ml}$ electrode.

2009; Tans et al., 1998). It is believed that the same mechanism is responsible for the observed increase in the signal current in the present work. An evidence for this mechanism was observed by reversing the polarity of $V_{G}$. A negative $V_{G}$ reverses the direction of the induced field and therefore increases the effective height of the tunnel barrier (Snow et al., 1988). Fig. 2(c) shows the effect of increasing $V_{G}$ in the negative polarity on the signal current. The LVs were obtained with progressively increasing $V_{G}$ in the negative polarity. The decrease in the signal current appears to be obvious 
(a)

(c)

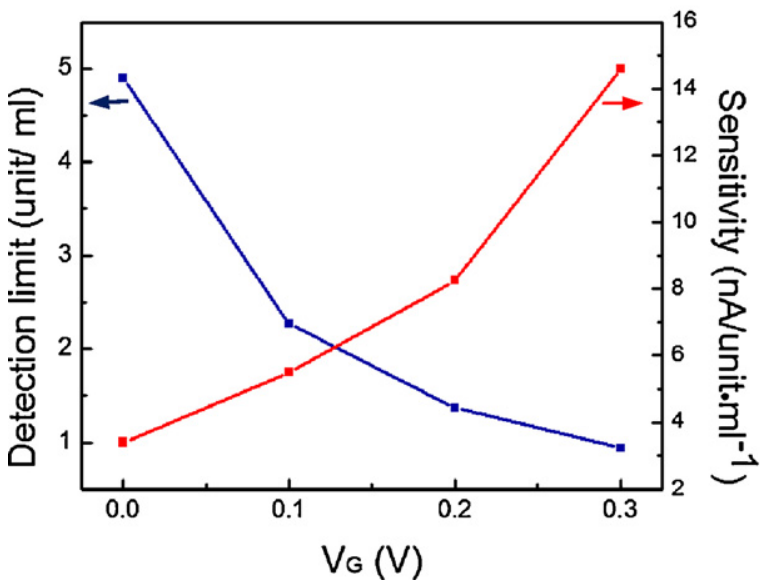

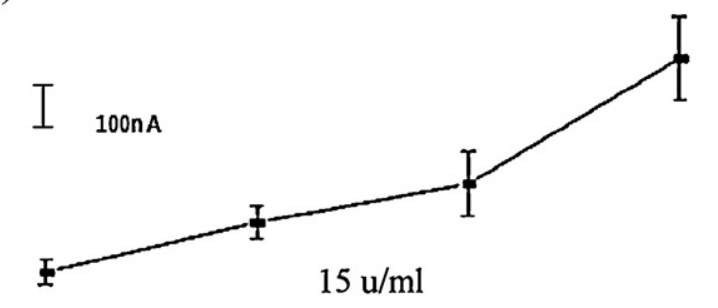

(b)
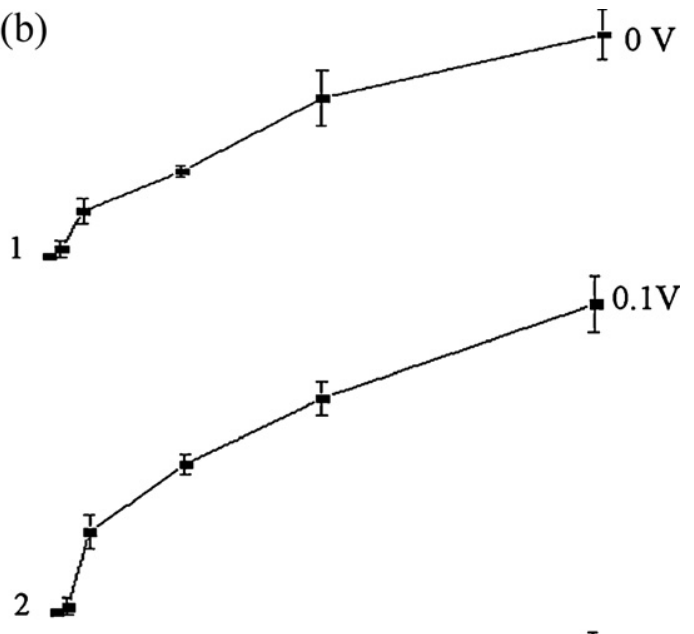

$3 \mathrm{u} / \mathrm{ml}$

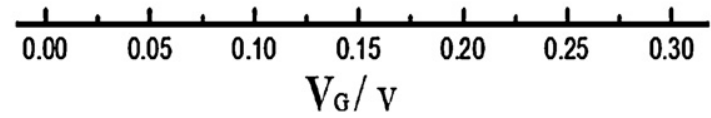

\subsection{0}
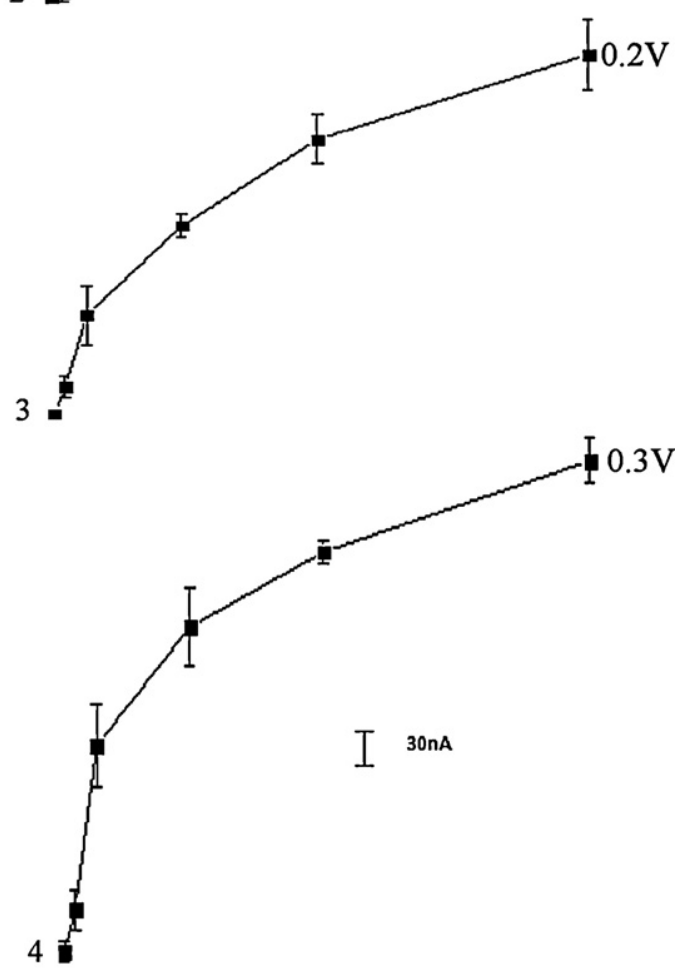

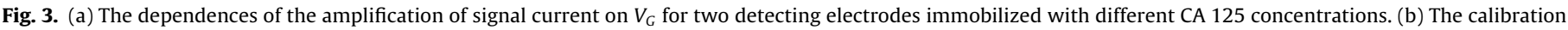

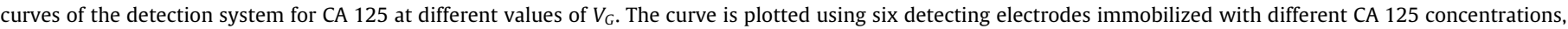
namely, $3 \mathrm{U} / \mathrm{ml}, 7 \mathrm{U} / \mathrm{ml}, 15 \mathrm{U} / \mathrm{ml}, 50 \mathrm{U} / \mathrm{ml}, 100 \mathrm{U} / \mathrm{ml}$, and $200 \mathrm{U} / \mathrm{ml}$. (c) Plots of the detection limit and sensitivity of the detection system vs. $V_{G}$.

with the aid of the baseline. The decrease in the signal supports the scenario of a modified tunnel barrier.

The increase of the signal current as shown in Fig. 2(b) indicates that the detection signal is amplified by varying $V_{G}$. Fig. 3(a) shows the voltage-controlled signal amplifications observed with two detecting electrodes incubated with solutions of different CA-125 concentrations. Both curves show that as $V_{G}$ is increased, the signal current increases. In particular, the amplification curves (including those obtained with electrodes incubated with other CA-125 concentrations) show a slightly nonlinear increase as $V_{G}$ is increase from $0.2 \mathrm{~V}$ to $0.3 \mathrm{~V}$. This effect reflects the fact that the amplification indicated by each curve is caused by the same mechanism, the modified tunnel barrier, while the difference between the signal magnitudes of the curves is due to the presence of different amount of CA-125. The double-arrow sign in Fig. 3(a) indicates that the amplification is controlled reversibly by $V_{G}$. Note that if $V_{G}$ is increased beyond $0.3 \mathrm{~V}$, the signal current will show a reversible inverse dependence on $V_{G}$, which is explained previously in terms of reversible re-orientation of the enzyme molecule on the electrode by the induced field (Choi and Yau, 2011). In the present case, field-initiated reorientation of the antigen, CA 125, is also a possible cause for the effect described.

The amplification of the detection signal has significantly improved the performance of the detection system. The detection system's calibration curves for CA 125 obtained with different values of $V_{G}$ using six detecting electrodes $(3,7,15,50,100,200 \mathrm{U} / \mathrm{ml})$ are shown in Fig. 3(b). Curve 1, obtained for $V_{G}=0 \mathrm{~V}$ and shown in Fig. 2(a), is displayed here for comparison. Curves 2-4 were obtained with different values of $V_{G}$ as indicated in the figure. All curves show a linear region for low CA 125 concentrations and a saturation region at higher concentrations. Since the linear regions of Curve 1 and Curve 2 are virtually determined by two points, we discuss curve fitting details for Curve 3 and Curve 4 only. The regression equation used is $y=b x+a$, where $b$ is the slope and $a$ is 
the $y$ intercept. In particular, $y=0.03078 x+0.41636$ was used for Curve 3 and $y=0.03415 x+0.97441$ was used for Curve 4 . The correlation coefficients for the two curves are 0.84517 and 0.85783 , respectively.

As stated above, in the absence of $V_{G}$, the CA 125 detection limit is $4.9 \mathrm{U} / \mathrm{ml}$. The curves show that as $V_{G}$ is increased, the signal current level increases. In particular, the current span of the linear range becomes wider accompanied with an increase in its slope. Comparing the linear range of the curves shows that $V_{G}$ improves the detection limit, detection resolution and the sensitivity of the detection system. As the result of increasing $V_{G}$ to $0.3 \mathrm{~V}$, the detection limit is lowered to $0.9 \mathrm{U} / \mathrm{ml}$ and the detection system is able to detect $3 \mathrm{U} / \mathrm{ml} \mathrm{CA} 125$. The error bar of the $3 \mathrm{U} / \mathrm{ml}$ data point is clearly separated from that of the $7 \mathrm{U} / \mathrm{ml}$ data point. Fig. 3(c) shows the dependences of the sensitivity and the detection limit of the detection system on $V_{G}$. The sensitivity is increased from 1 to about $15 \mathrm{nA} / \mathrm{U} \mathrm{ml}^{-1}$ as $V_{G}$ is increased from 0 to $0.3 \mathrm{~V}$. The 5 -fold increase in sensitivity is significant since it causes the detection limit to be lowered from 4.9 to $0.9 \mathrm{U} / \mathrm{ml}$.

\section{Conclusions}

The present work has demonstrated that the application of the gating voltage has caused reversible amplification of the detection signal of a modified amperometric immuno-detection system. The amplification has in turn improved the performance of the detection system in terms of lowering the detection limit, increasing the detection resolution and detection sensitivity. The method used to prepare the detecting electrodes indicates that the detection approach can be used as a general assay methodology for biomarkers. The low detection limit obtainable via the application of $V_{G}$ makes the detection method particularly suitable for the early detection of cancer recurrence. Additionally, the reagentless approach, in which no mediators or enzyme substrates is required, is compatible with the requirement for point-of-care approach of biomarker assay.

\section{Acknowledgements}

This work was supported by American Diabetes Association (Grant number 7-08-RA-191) and by Cleveland State University (Research Challenge Award).

\section{Appendix A. Supplementary data}

Supplementary data associated with this article can be found, in the online version, at doi:10.1016/j.bios.2011.07.072.

\section{References}

Andreu, R., Ferapontova, E.E., Gorton, L., Calvente, J.J., 2007. J. Phys. Chem. B 111 469-477.

Boerman, O., Massuger, L., Makkink, K., Thomas, C., Kenemans, P., Poels, L., 1990. Anticancer Res. 10 (5A), 1289-1295.

Bollo, S., Ferreyra, N.F., Rivas, G.A., 2007. Electroanalysis 19, 833-840.

Chiodarelli, N., Masahito, S., Kashiwagi, Y., Li, Y., Arstila, K., Richard, O., Cott, D.J., Heyns, M., Gendt, S.D., Groeseneken, G., Vereecken, P.M., 2011. Nanotechnology 22, 085302.

Choi, Y., Yau, S.-T., 2009. Anal. Chem. 81, 7123-7126.

Choi, Y., Yau, S.-T., 2011. Biosens. Bioelectron. 26, 3386-3390.

Ferri, T., Poscia, A., Santucci, R., 1998. Bioelectrochem. Bioenerg. 44, 177-181.

Nakazawaa, T., Oshidaa, K., Onoa, N., Ohsawaa, K., Endob, M., Bonnamy, S., 2004 Thin Solid Films 464-465, 360-363.

Rasooly, A., Jacobson, J., 2006. Biosens. Bioelectron. 21, 1851-1858.

Snow, E.S., Campbell, P.M., Rendell, R.W., Buot, F.A., Park, D., Marrian, C.R.K., Magno, R., 1988. Appl. Phys. Lett. 72, 3071-3073.

Tans, S.J., Verschueren, A.R.M., Dekker, C., 1998. Nature 393 (49 393), 49-52.

Thaxton, C.S., Elghanian, R., Thomas, A.D., Stoeva, S.I., Lee, J.-S., Smith, N.D., Schaeffer, A.J., Klocker, H., Horninger, W., Bartsch, G., Mirkin, C.A., 2009. PNAS 106 18437-18442.

Wang, J., 2005. Electroanalysis 17, 7-14

Wang, J., 2006. Biosens. Bioelectron. 21, 1887-1892.

Warsinke, A., 2009. Anal. Bioanal. Chem. 393, 1393-1405.

Weiss, D.J., Dorris, M., Loh, A., Peterson, L., 2007. Biosens. Bioelectron. 22, $2436-2441$.

Wilson, M.S., 2005. Anal. Chem. 77, 1496-1502.

Wu, L., Yan, F., Ju, H., 2007. J. Immunol. Methods 322, 12-19.

Yu, X., Kim, S.N., Papadimitrakopoulos, F., Rusling, J.F., 2005. Mol. BioSyst. 1, $70-78$

Zhang, Y., He, P., Hu, N., 2004. Electrochim. Acta 49, 1981-1988. 